\title{
Hamman's syndrome: spontaneous pneumomediastinum and subcutaneous emphysema during second stage of labour
}

\author{
Ying Yiing Lou* \\ Department of Obstetrics and Gynecology, Watford General Hospital, Watford, United Kingdom \\ Received: 06 April 2017 \\ Accepted: 02 May 2017 \\ *Correspondence: \\ Dr. Ying Yiing Lou, \\ E-mail: yingyiing.lou@nhs.net \\ Copyright: $\odot$ the author(s), publisher and licensee Medip Academy. This is an open-access article distributed under \\ the terms of the Creative Commons Attribution Non-Commercial License, which permits unrestricted non-commercial \\ use, distribution, and reproduction in any medium, provided the original work is properly cited.
}

\begin{abstract}
Subcutaneous emphysema with pneumomediastinum in labour is also known as Hamman's Syndrome. Maternal pneumomediastinum associated with subcutaneous emphysema is a rare complication of pregnancy. The incidence rate being between 1:2000 and 1:10,000. Pneumomediastinum occurs most frequently in the second stage of labour in a healthy primiparous women with prolonged labour. A 29 -year-old primigravida, who had no relevant medical history, had an uneventful spontaneous vaginal delivery at term. She used Entonox as analgesia in labour. She developed facial and neck oedema associated with mild breathing discomfort towards the end of her second stage. Crepitus was felt in her cheek, neck and anterior chest wall. Observations were stable including oxygen saturation. Chest X-ray demonstrated gross and extensive surgical emphysema across the chest and up into the neck and with no evidence of pneumothorax. She was managed conservatively and the subcutaneous emphysema was found to have considerably better within 24 hours. She recovered uneventfully and was discharged within 3 days of admission. A future pregnancy is planned. Hamman's syndrome is generally a self-limiting condition. The key to successful management is early recognition followed by appropriate measures to prevent further complications in order to reduce the morbidity and mortality associated with this condition. Supportive measures alone may be the only requirement for resolution. Recurrence of the condition is rare but the appropriate management of subsequent pregnancies is unclear. Our case was appropriately managed with multidisciplinary input in the HDU on labour ward.
\end{abstract}

Keywords: Hamman's syndrome, Pneumoperitoneum, Subcutaneous emphysema

\section{INTRODUCTION}

Maternal pneumomediastinum associated with subcutaneous emphysema is a rare complication of pregnancy which was described by Hamman in $1945 .{ }^{1}$ It has an estimated incidence between 1:2000 and $1: 10,000 .^{2}$ It was first mentioned in 1618 by Louise Bourgeois, midwife to the Queen of France, but they syndrome was not formally described until Hamman defined it. Only 200 cases have been reported so far in the literature. ${ }^{3}$ This case report illustrates the simplicity of diagnosis and reminds obstetric personnel that the outcome is almost favourable, although the potential for complicated outcomes is always present.

\section{CASE REPORT}

A 29-year-old primigravida had an uneventful antenatal course. Her past medical history was unremarkable except for mild asthma. She had never smoked and had no significant exposure to second-hand smoke. Her prepregnancy body mass index was $26 \mathrm{~kg} / \mathrm{m}^{2}$.

She presented at 39 weeks of gestation in spontaneous labour. Her cervix was found to be at $8 \mathrm{~cm}$ dilated on 
admission. She was coping well with Entonox and in ambulatory position. Her cervix was fully dilated 2 hours after admission. Active pushing with forceful expulsive 'pushing down' movement was commenced following after her last vaginal examination and a live male infant weighing $3820 \mathrm{~g}$ was delivered an hour later with good Apgar scores of 9 and 10 at 1 and 5 minutes respectively.

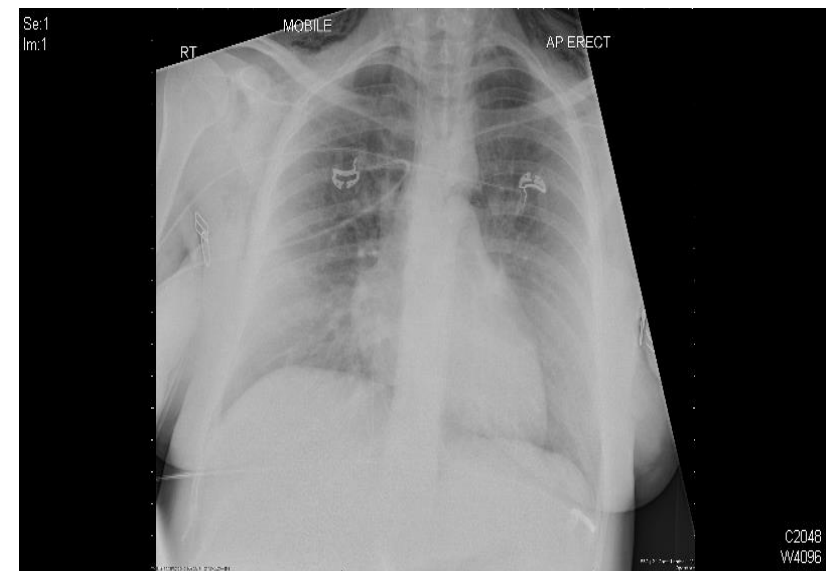

Figure 1: AP chest X-ray 1 hour after delivery, showing subcutaneous air.

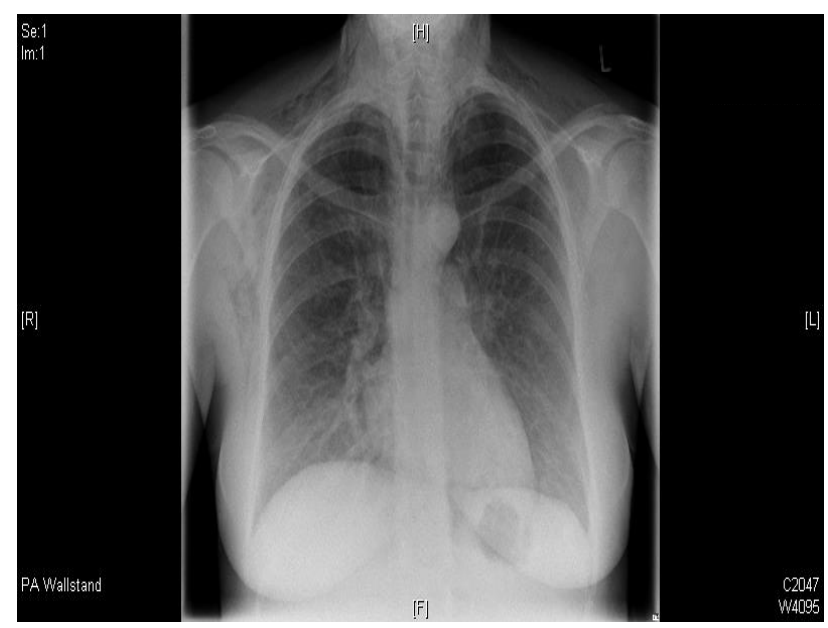

Figure 2: AP chest X-ray 17 hours postpartum.

She was noticed to have significant facial oedema and her face looked flushed as if she had an allergy reaction a few minutes just before her delivery. She had mild breathing discomfort but she was not tachypnoeic. Respiratory rate was 18 breaths/minute. There was no associated chest pain, palpitation, sweats or nausea. On examination, she was comfortable. Haemodynamically, she was stable. She was neither pale nor cyanosed. Her oxygen saturation was $99 \%$ on air. Crepitus was felt in her cheek, neck and anterior chest wall. There was no tracheal deviation and the air entry was equal bilaterally. She was transferred to High Dependency Unit (HDU) on labour ward. An electrocardiogram (ECG) showed sinus tachycardia with no acute ECG changes. Chest $\mathrm{x}$-ray revealed gross and extensive surgical emphysema across the chest and up into the neck and with no evidence of pneumothorax
(Figure 1). A day later the subcutaneous emphysema was found to have considerably better and her CXR confirmed partial resolution (Figure 2). She was well managed conservatively and she recovered uneventfully within 3 days.

\section{DISCUSSION}

Subcutaneous emphysema with pneumomediastinum in labour is also known as Hamman's Syndrome. It usually occurs during the second stage of labour, related to the valsalva manoeuvre during the expulsive phase of labour where 'pushing down' acutely raises intra-alveolar pressure. It is thought that the increased intrathoracic pressure, in the presence of decreased vascular calibre, establishes a pressure gradient into the vascular sheath along which air can then dissect into the mediastinum and subsequently tracks though the fascial planes into subcutaneous tissues. ${ }^{4}$ In present case, it is speculated that active pushing with forceful expulsive 'pushing down' movement could have been contributed to this condition.

The diagnosis of subcutaneous emphysema is selfevident. The most important clinical feature is palpable crepitus on the face and the neck which is virtually due to subcutaneous emphysema. A simple chest X-ray will confirm the diagnosis and preclude other invasive tests and inappropriate treatment. ${ }^{2}$

In this case, clinical and radiological findings strongly suggested the diagnosis of spontaneous pneumomediastinum, an infrequent entity that should be considered for differential diagnosis of acute chest pain specially among young people without risk factors for ischaemic heart disease. Other differential diagnosis of acute postpartum chest pain may, amongst other causes, be due to a pulmonary embolus, aortic dissection, or myocardial infarction.

Patients with Hamman's syndrome usually have a good outcome with conservative management and serious complications are exceptional. ${ }^{5}$ Supportive measures alone may be the only requirement for resolution. With continuous oxygen saturations of $99 \%$, it was felt that supplemented oxygen was not required. Some reports suggest that supplemental oxygen may lead to faster resolution of the pathological changes. ${ }^{6}$ However, this is unproven. In this case, resolution occurred within 3 days without oxygen administration.

It was reported that use of Entonox analgesia is probably relative contraindicated because it is likely to cause further expansion of the pneumomediastinum. ${ }^{6}$ Use of regional anaesthesia would also facilitate expedited operative delivery. To avoid such complications, shortening the second stage of labour by the use of forceps or vacuum extraction is recommended when pneumomediastinum has been diagnosed. 
Identification of subcutaneous emphysema is important because potential complications can be serious like as there are life-threatening complications such as amniotic fluid embolism, pulmonary embolism, pneumothorax, myocardial infarction and aortic dissection leading to cardiac failure. ${ }^{7}$ It is important to consider invasive and aggressive management if evidence of cardiovascular instability develops due to potential for increased morbidity and mortality.

An issue of concern is that this patient wishes to consider having further pregnancies. Patients should be counselled that there is no increased risk of recurrence in the subsequent pregnancies. $^{8}$ However, there is limited published experience and the proper management of subsequent deliveries is controversial. Expectant management of subsequent labour and delivery using epidural analgesia is suggested in anticipation of a spontaneous vaginal delivery.

Recurrence of the condition is rare, but the appropriate management of subsequent pregnancies is unclear. $^{9}$ Expectant management with epidural analgesia to minimize active pushing is suggested in a subsequent spontaneous vaginal delivery. Published reports indicate that subsequent pregnancies pose no additional risk for recurrence. ${ }^{10}$ Some authors state that recurrence of Hamman's syndrome has never been reported, but others note two episodes of recurrence occurring prior to 1900 . There is no evidence to specify an appropriate interval that should elapse before the next conception. ${ }^{7}$

The proper management of subsequent deliveries is controversial. Older publications advocate withholding active pushing in favour of low forceps delivery. More recent opinions recommend expectant management only, with instrumental delivery being performed on clinical grounds as determined in each case. In the absence of strong evidence to support either course of action, expectant management seems to be the appropriate course to follow. The use of epidural analgesia is suggested in order to control the possibility of involuntary maternal bearing down or pushing. ${ }^{5}$

\section{CONCLUSION}

It is essential that pneumomediastinum is recognised and treated promptly. Although it follows self-limiting course, once suspected, it is important to avoid inhalational analgesia, to shorten the active second stage of labour and involve physicians to avoid potential complications. In present case, it was appropriately managed with multidisciplinary input in the HDU on labour ward.
Recurrence is rare, and there is little evidence to guide the management of subsequent pregnancies. Expectant management of subsequent labour and delivery using epidural analgesia is suggested in anticipation of a spontaneous vaginal delivery.

Funding: No funding sources

Conflict of interest: None declared

Ethical approval: Not required

\section{REFERENCES}

1. Hamman L. Mediastinal emphysema. JAMA. 1956;128:1-6.

2. Balkan ME, Alver G. Spontaneous pneumomediastinum in 3rd trimester of pregnancy. Ann Thorac Cardiovasc Surg. 2006;12(5):362-4.

3. Reeder SR. Subcutaneous emphysema, pneumomediastinum and pneumothorax in labour and delivery. Am J Obstet Gynecol. 1986;154:487-9.

4. Weinberger SE, Weiss ST. Pulmonary disease. In: Burrows GN, Ferris TR. Medical complications during pregnancy. 3rd ed. Philadelphia, Pa: WB Saunders; 1988:474-5.

5. Barge-Caballero E, Bouzas-Mosquera A, GuliasSoidan D, Castro-Beiras A. Hamman's syndrome: an atypical cause of chest pain. Eur Heart J. 2007;29(5):578.

6. Grean PA, Stronge JM, FitzGerald MX. Spontaneous penumomediastinum in pregnancy. $\mathrm{Br} \mathrm{J}$ Obstet Gynaecol. 1981;88(9):952-4.

7. Jayran-Nejad Y. Subcutaneous emphysema in labour. Anaesthesia. 1993;48(2):139-40.

8. Raley JC, Andrews JI. Spontaneous pneumomediastinum presenting as jaw pain during labour. Obstet Gynecol. 2001;98(5 Part 2):904-6.

9. Karson EM, Saltzman D, Davis MR. Pneumomediastinum in pregnancy: two case reports and a review of the literature, pathophysiology and management. Obstet Gynaecol. 1984;64:39S-43S.

10. Bonin MM. Hamman's syndrome (spontaneous pneumomediastinum) in a parturient: a case report. J Obstet Gynaecol Can. 2006;28(2):128-31.

Cite this article as: Lou YY. Hamman's syndrome: spontaneous pneumomediastinum and subcutaneous emphysema during second stage of labour. Int J Reprod Contracept Obstet Gynecol 2017;6:2622-4. 